\title{
Sistem Informasi Rekrutmen Karyawan Baru pada PT Karya Putra Sapta Manunggal Berbasis Web
}

\author{
Lia Fajarwati ${ }^{1}$, Rachmat Hidayat ${ }^{2}$, dan Yusnia Budiarti ${ }^{3}$ \\ ${ }^{1}$ Sistem Informasi, ${ }^{2,3}$ Teknik Informatika \\ ${ }^{1,3}$ Sekolah Tinggi Manajemen Informatika dan Komputer (STMIK) Nusa Mandiri, jl. Daan Mogot No.31 \\ Kota Tangerang, Banten, 15111 \\ ${ }^{2}$ Universitas Bina Sarana Informatika, jl. Kramat Raya No.98, RT.002/RW.009 Kwitang Kec.Senen, Kota \\ Jakarta Pusat, DKI Jakarta 10420 \\ e-mail: ${ }^{1}$ Liafajarwa@ gmail.com , ${ }^{2}$ Rachmat.rch@bsi.ac.id, ${ }^{3}$ Yusnia.ybi@ nusamandiri.ac.id
}

Submitted Date: October 22 ${ }^{\text {nd }}, 2020$

Revised Date: November $08^{\text {th }}, 2020$
Reviewed Date: October $30^{\text {th }}, 2020$

Accepted Date: November $17^{\text {th }}, 2020$

\begin{abstract}
PT Karya Putra Sapta Manunggal is a company in the field of construction services based in Bekasi. In recruiting employees, PT Karya Putra Sapta Manunggal still uses conventional methods, namely that prospective employees usually send application files to the head office in Bekasi either by e-mail, post or by submitting applications directly to the Admin section. HRDs need to open e-mails and application files one by one which makes HRDs have to process applicants' data again, resulting in a high probability of errors. Therefore, it is necessary to create a new and effective system in order to facilitate the recruitment of employees using a system development methodology, namely the waterfall method. With the PHP programming language, codeigniter framework and mysql database, the employee recruitment website makes it easier for HRD to minimize time, costs and energy so that the recruitment process becomes more efficient. In addition, delivering clear and up-to-date information will improve the company's image.
\end{abstract}

Keywords: Recruitment; New Employees; PHP; CodeIgniter.

\section{Abstrak}

PT Karya Putra Sapta Manunggal merupakan perusahaan di bidang jasa konstruksi yang berpusat di Bekasi. Dalam merekrut karyawan, PT Karya Putra Sapta Manunggal masih menggunakan cara yang konvensional yaitu calon karyawan biasanya mengirimkan berkas lamaran ke kantor pusat yang berada di Bekasi baik melalui e-mail, pos maupun menitipkan lamaran langsung di bagian Admin. HRD perlu membuka $e$-mail dan berkas lamaran satu persatu yang membuat HRD harus mengolah lagi data pelamar sehingga mengakibatkan besarnya kemungkinan terjadi kesalahan. Maka dari itu perlu dibuatnya sistem yang baru dan efektif supaya memudahkan dalam perekrutan karyawan dengan menggunakan metodologi pengembangan sistem yaitu dengan metode waterfall. Dengan bahasa pemrograman PHP, framework codeigniter dan basis data mysql website perekrutan karyawan memudahkan HRD dalam meminimalisir waktu, biaya dan tenaga sehingga proses rekrutmen menjadi lebih efisien. Selain itu, penyampaian informasi secara jelas dan terbaru akan membuat citra perusahaan menjadi semakin baik.

Kata kunci: rekrutmen; karyawan baru; PHP; Codeigniter 


\section{Pendahuluan}

Salah satu aspek penting yang berharga dalam suatu perusahaan yaitu sumber daya manusianya. Selain sumber daya manusia ada juga sumber daya lain seperti material, mesin, uang, dan informasi. Namun, sumber daya lain tersebut hanya dapat memberikan hasil optimal jika sumber daya manusianya mampu untuk mengelola(Yulistia, Lesmono, and Harefa 2020). Karena sumber daya manusia inilah yang nantinya akan melakukan segala kegiatan operasional di perusahaan, maka untuk menjaring sumber daya manusia dilakukan proses perekrutan. Perekrutan merupakan proses awal suatu perusahaan untuk menjaring sumber daya manusia dengan kualitas yang mumpuni dan memiliki potensi(Desanti and Widjaja 2018). Dalam merekrut karyawan pun tentunya tidak bisa sembarangan, karena karyawan yang direkrut seharusnya karyawan yang memiliki kualifikasi sesuai dengan posisi yang tersedia.

PT Karya Putra Sapta Manunggal merupakan perusahaan di bidang jasa konstruksi yang berpusat di Bekasi. Dalam merekrut karyawan, PT Karya Putra Sapta Manunggal masih menggunakan cara yang konvensional yaitu calon tenaga kerja biasanya mengirimkan berkas lamaran ke kantor pusat yang berada di Bekasi baik melalui email, pos maupun menitipkan lamaran langsung di bagian Admin.

HRD biasanya akan memakan waktu yang cukup lama dalam proses seleksi karena HRD harus mengecek dan mendata ulang data pelamar dari berkas lamaran yang masuk. HRD perlu membuka email maupun berkas lamaran satu persatu yang membuat HRD harus mengolah lagi data pelamar sehingga mengakibatkan besarnya kemungkinan terjadi kesalahan.

Maka dari itu perlu dibuatnya sistem yang baru dan efektif supaya memudahkan dalam perekrutan karyawan dengan menggunakan metodologi pengembangan sistem yaitu dengan metode waterfall. Kemungkinan untuk terjadi kesalahan akan minim sekali jika menggunakan metode waterfall, karena proses pengembangan ini dikerjakan satu per satu.

Sistem informasi rekrutmen karyawan baru ini akan memudahkan HRD dalam memilih calon karyawan yang sesuai kriteria perusahaan. HRD dapat memperbarui info posisi yang sedang tersedia dan mengelola data calon karyawan. Sedangkan calon karyawan sendiri bisa mengelola akun, melamar pekerjaan dan mengerjakan soal ujian seleksi melalui sistem ini.

\section{Landasan Teori}

Berikut adalah landasan teori yang berhasil penulis rangkum dari beberapa sumber:

a. Sistem

Sistem merupakan komponen komponen yang dikumpulkan dari bentuk fisik ataupun non fisik supaya suatu tujuan tercapai dengan cara yang harmonis.(Dedy Rahman Prehanto, S.Kom. 2020a)

b. Informasi

Informasi merupakan kumpulan data yang diolah supaya memiliki nilai guna bagi penerimanya.(M. FIRMAN ARIF, S.Kom. 2019)

c. Sistem informasi

Sistem Informasi merupakan kumpulankumpulan sub sistem, baik berupa dalam bentuk fisik atau bahkan berbentuk abstrak yang berintegrasi serta adanya kolaborasi dengan cara mengumpulkan data yang diolah sehingga data tersebut memiliki nilai tambah serta memiliki manfaat bagi pengguna untuk mencapai suatu tujuan(Taufiq 2018).

d. Website

Website merupakan kumpulan dari informasi baik gambar, teks, maupun video yang disajikan berbentuk laman-laman dan diakses melalui internet(Eko Junirianto 2018).

e. Internet

Internet merupakan jaringan komputer satu dengan jaringan computer lain yang saling terhubung dan digunakan website untuk mengirim suatu informasi.(Abdulloh 2016).

f. Rekrutmen

Rekrutmen merupakan kegiatan perusahaan dengan penyebaran informasi untuk membuka akses seluas-luasnya yang berguna untuk menjaring pelamar (Hariwijaya 2017).

g. PHP

Php merupakan jenis bahasa pemrograman untuk menerjemahkan suatu baris kode program agar menjadi bahasa yang dimengerti oleh mesin dan komputer yang sifatnya server-side(Supono and Putratama 2018).

h. Codeigniter

Codeigniter merupakan kerangka kerja bahasa pemrograman php yang menggunakan metode model, metode view dan metode controller atau biasa kita sebut dengan MVC(Habibi and Sandi 2020).

i. MySQL

MySQL merupakan aplikasi perangkat lunak open source yang biasa digunakan untuk memanajemen sistem basis data SQL (biasa 
disebut query) atau DBMS yang bersifat multithread, multi-user(Canggih Ajika Pamungkas 2017).

j. UML

UML merupakan bahasa grafis yang digunakan sebagai alat pendokumentasian dan sebagai alat untuk melakukan spesifikasi sistem dengan menggunakan teknik pengembangan sistem(Mulyani 2016).

k. Use case diagram

Diagram use caseluse case diagram merupakan model yang tujuannya untuk menjelaskan proses sistem atau alur menggunakan simbol(Dedy Rahman Prehanto, S.Kom. 2020b).

l. Activity diagram

Adapun Activity Diagram yaitu merupakan penggambaran aktivitas alur kerja pada logika, use case, proses bisnis serta hubungan diantara aktor dengan alur kerja suatu use case berbentuk diagram(Mulyani 2016).

m. Waterfall

Waterfall merupakan metode pembangunan perangkat lunak berdasarkan daur hidup perangkat lunak atau biasa disebut SDLC dan setiap fase dalam waterfall harus menyelesaikan fase awal dahulu sebelum mengerjakan fase selanjutnya yang menjadi ciri khas dalam pengerjaan metode ini(Yurindra 2017).

\section{Metodologi Penelitian}

Metodologi dalam pengembangan sistem yang penulis pakai yaitu memakai metode waterfall. Aktivitas-aktivitas dalam pengembangan metode waterfall di antaranya:

a. Analisa kebutuhan sistem

Untuk menunjang kegiatan perekrutan di PT Karya Putra Sapta Manunggal, maka perlu adanya sistem informasi rekrutmen karyawan yang berbasis website. Dengan memanfaatkan internet dan melakukan hosting, maka akan memudahkan perusahaan dalam menyebarkan informasi ketika sedang mengadakan proses rekrutmen karyawan.

b. Desain

Untuk membuat gambaran sistem yang akan dibuat maka diilustrasikan ke dalam desain. Desainnya sendiri mencakup ERD, UML, LRS, detail masukan dan keluaran dengan menggunakan Enterprise Architect. Untuk desain basis datanya menggunakan mysql. Desain ini lah yang akan menjadi gambaran bagi penulis dan mengimplementasikannya dengan pengodean.

c. Code generation

Penulis mengubah desain pada program yang telah dibuat ke bentuk bahasa pemrograman dengan menggunakan bahasa pemrograman php, javascript, html, css, dan bootstrap. Dengan menggunakan codeigniter sebagai framework dan basis data mysql.

d. Testing

Setelah program telah selesai dibuat, pelu adanya uji coba untuk menguji kelayakan program agar mudah digunakan. Uji coba ini sendiri untuk memastikan sistem yang telah dibuat terbebas dari error dan sistem ini sudah sesuai agar mudah digunakan. Dalam melakukan uji coba ini penulis memakai metode black box testing. Metode pengujian black box adalah pengujian yang memverifikasi hasil eksekusi aplikasi berdasarkan masukan yang diberikan (data uji) untuk memastikan fungsional dari aplikasi sudah sesuai dengan persyaratan (requirement) (Febrian, Ramadhan, Faisal, \& Saifudin, 2020).

e. Support

Untuk menunjang pembuatan dan pemeliharaan sistem rekrutmen ini penulis membutuhkan perangkat keras dengan spesifikasi Core i3, RAM 4 GB dan hardisk 1 TB.

\section{Hasil dan Pembahasan \\ 4.1. Analisa kebutuhan sistem}

Sistem informasi penerimaan karyawan baru ini akan memudahkan HRD dalam memilih calon karyawan yang sesuai kriteria perusahaan. HRD dapat memperbarui info posisi yang sedang tersedia dan mengelola data calon karyawan. Sedangkan calon karyawan sendiri bisa mengelola akun, melamar pekerjaan dan mengerjakan soal ujian seleksi pada sistem ini.

\subsection{Desain Sistem}

a. Use case halaman calon karyawan melamar pekerjaan 


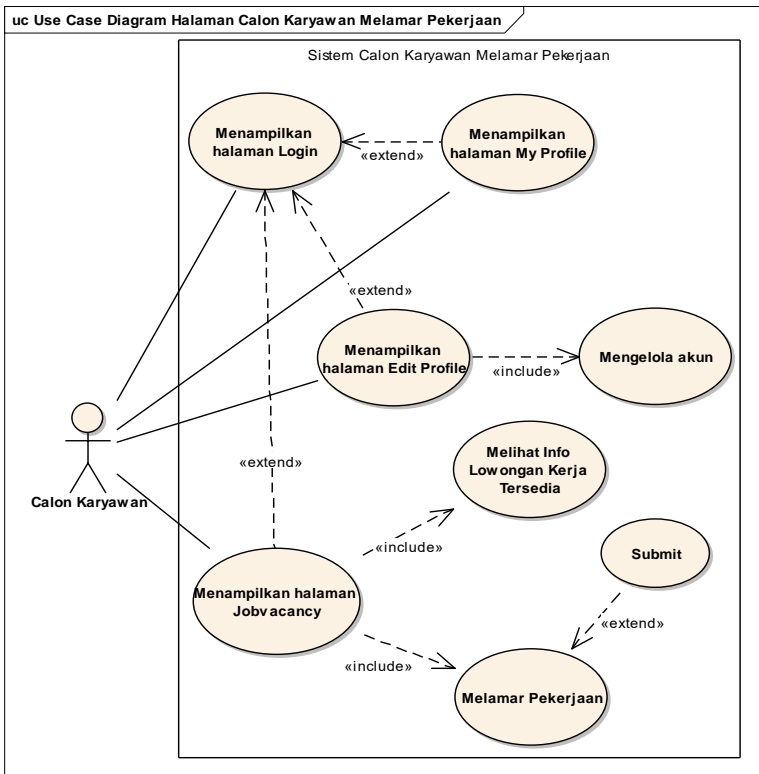

Gambar 1 gambar use case diagram halaman calon karyawan melamar pekerjaan

Gambar 1 merupakan gambaran sistem rekrutmen di mana calon karyawan yang telah melakukan registrasi/pendaftaran maka dapat melihat halaman My Profile, Edit Profile, dan halaman Jobvacancy yaitu halaman untuk melakukan proses melamar pekerjaan. Calon karyawan dapat melihat info lowongan kerja apa saja yang sedang tersedia, lalu melamar posisi pada bagian yang diinginkan.

b. Use case halaman calon karyawan mengerjakan soal ujian seleksi

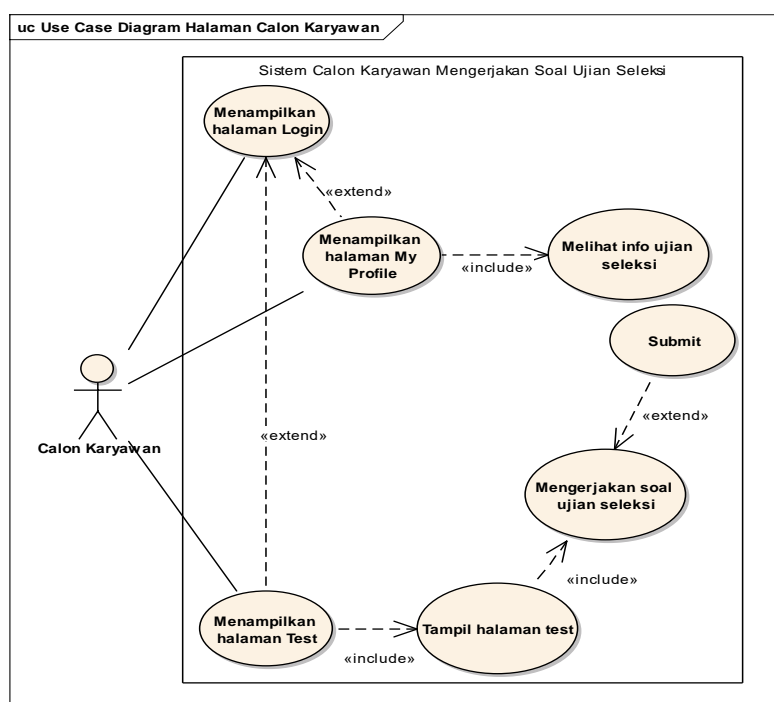

Gambar 2 gambar use case halaman calon karyawan mengerjakan soal ujian seleksi
Gambar 2 menggambarkan sistem ketika calon karyawan telah melamar pekerjaan. Setelah data calon karyawan diverifikasi oleh HRD/Admin maka calon karyawan akan menerima info ujian seleksi dan bisa mengerjakan ujian seleksi melalui halaman tes.

c. Use case halaman hrd/admin mengelola informasi lowongan kerja

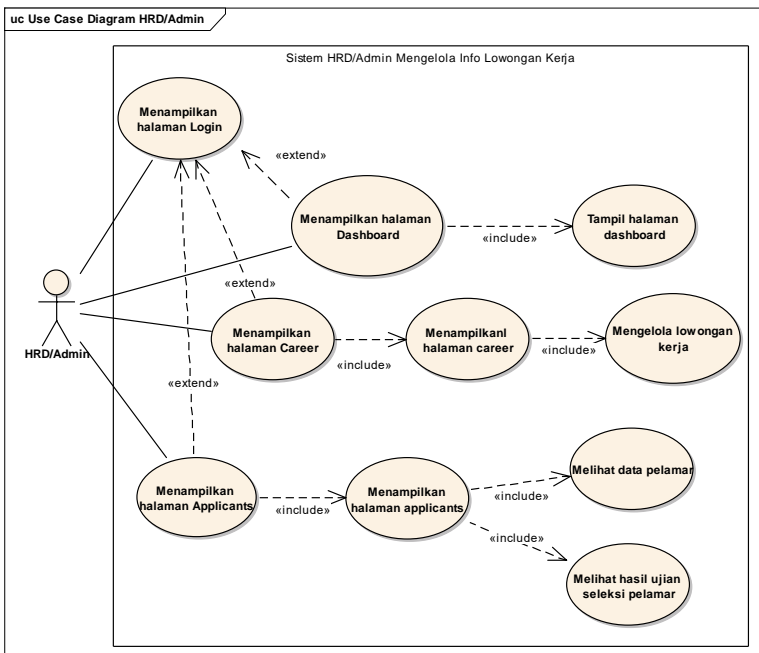

Gambar 3 gambar use case diagram halaman hrd/admin mengelola info lowongan kerja

Gambar 3 menggambarkan sistem ketika HRD/Admin mengelola info lowongan kerja. Jadi HRD/Admin dapat memperbarui info lowongan yang sedang tersedia. Lalu setelah info lowongan kerja dipublikasi, maka HRD/Admin dapat melihat siapa saja kandidat/calon karyawan yang telah melamar dan memverifikasi data kandidat yang telah melamar. HRD/Admin juga dapat melihat hasil ujian tes para calon karyawan yang telah mengerjakan soal ujian seleksi.

d. Activity diagram halaman calon karyawan melamar pekerjaan 


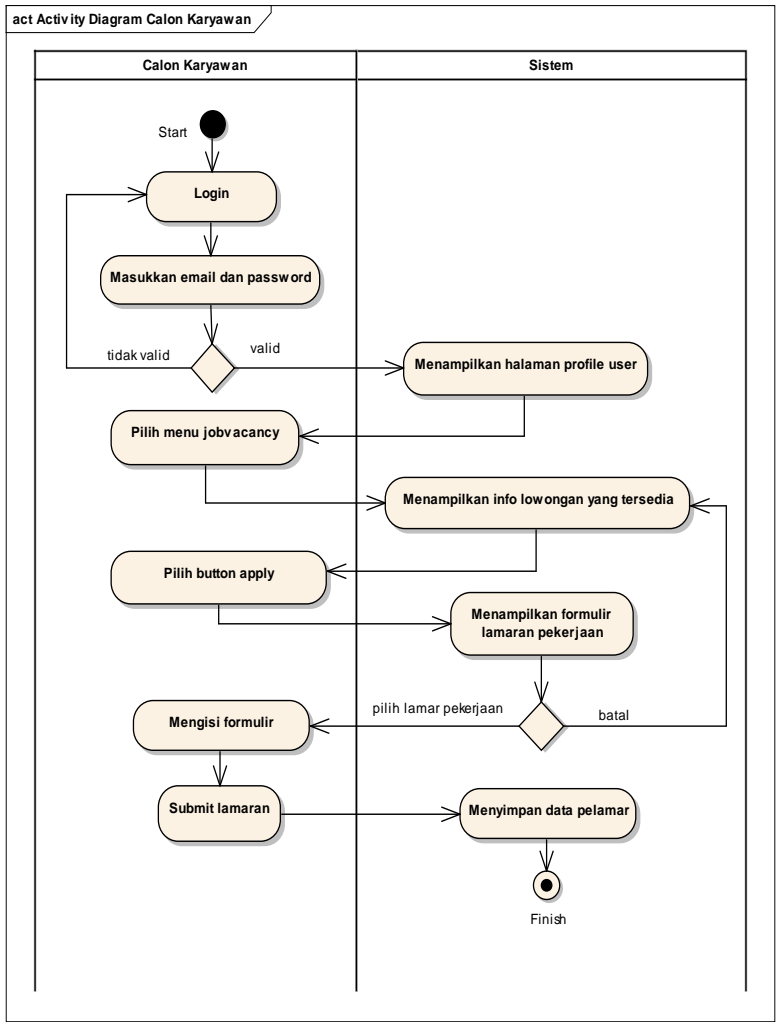

Gambar 4 gambar activity diagram calon karyawan melamar pekerjaan

Gambar 4 merupakan activity diagram dari proses calon karyawan yang melamar pekerjaan. Dimulai dari calon karyawan yang melakukan login dengan email dan password lalu jika email dan password datanya valid maka akan diteruskan ke halaman profil pengguna. Dan sebaliknya, jika data tidak valid maka tampil pesan error.

Pada proses ini, selanjutnya calon karyawan yang telah login nantinya bisa melihat posisi lowongan yang sedang tersedia lalu bisa memilih posisi yang diinginkan. Setiap posisi akan tercantum persyaratan yang berbeda-beda pada setiap posisi dan jika calon karyawan telah mendapatkan posisi yang sesuai maka dilanjutkan dengan mengisi formulir dan mengunggah berkasberkas yang diperlukan. Berikutnya tahap akhir dari proses melamar pekerjaan ini adalah dengan klik tombol kirim dan tinggal menunggu lamaran dari calon karyawan diverifikasi oleh pihak HRD/Admin.

e. Activity diagram halaman calon karyawan mengerjakan soal ujian seleksi

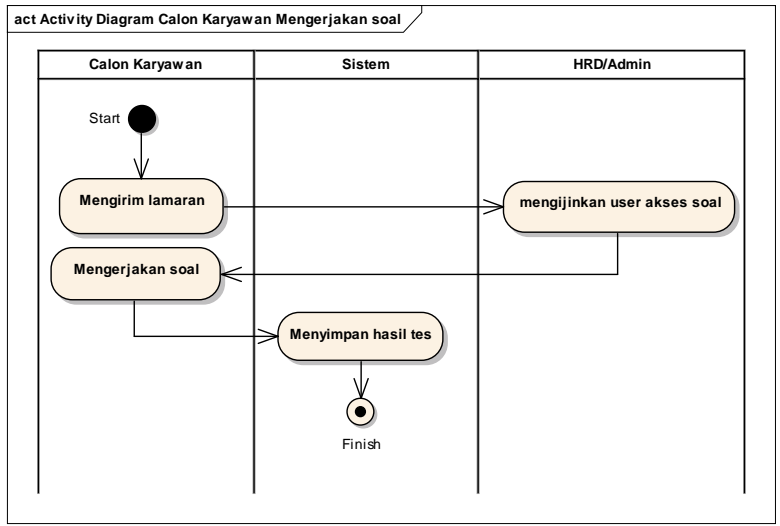

Gambar 5 gambar activity diagram calon karyawan mengerjakan soal ujian seleksi

Gambar 5 menerangkan bahwa calon karyawan yang telah mengirim lamaran dan data lamarannya berhasil diverifikasi oleh HRD/Admin maka HRD/Admin berhak mengijinkan calon karyawan mengakses soal ujian tes. Calon karyawan yang telah selesai mengerjakan soal ujian tes maka hasil tes akan disimpan oleh sistem. Dan hasil ujian seleksi nantinya akan ditinjau lagi oleh HRD/Admin sebagai bahan pertimbangan.

f. Activity diagram halaman hrd/admin mengelola informasi lowongan kerja

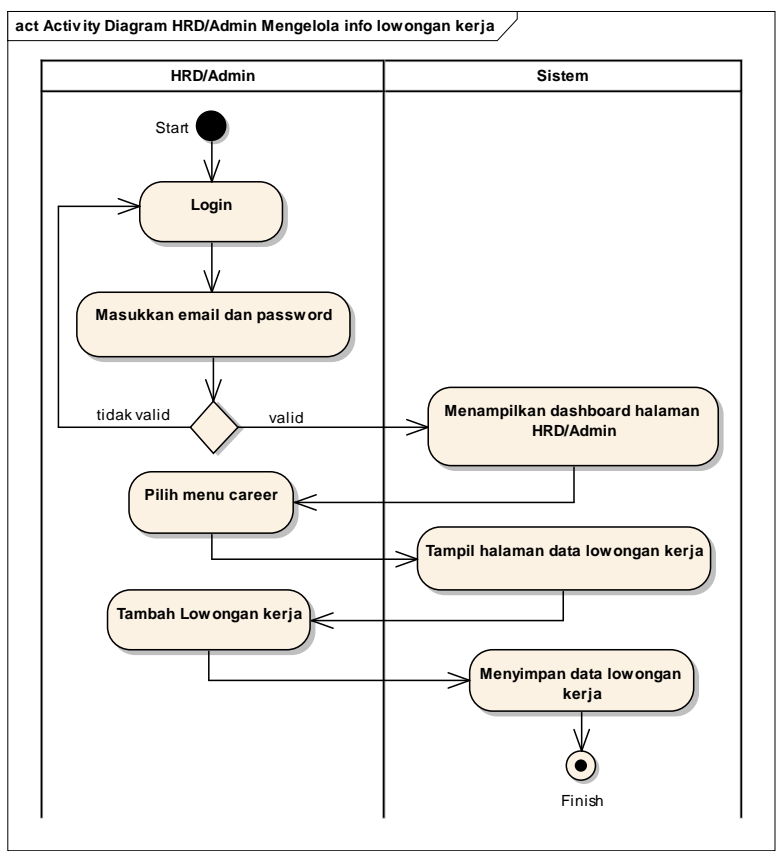

Gambar 6 gambar activity diagram hrd/admin mengelola informasi lowongan kerja

Gambar 6 menggambarkan proses HRD/Admin dalam mengelola informasi lowongan 
kerja. Jadi langkah awal yang dilakukan yaitu dengan membuka halaman login dan memasukkan email beserta password. Jika data tidak valid maka akan tampil pesan error. Namun jika email dan password valid maka akan dialihkan ke halaman HRD/Admin. Mengenai informasi lowongan kerja yang tersedia pada website, HRD/Admin dapat memperbarui informasi ini pada halaman karir.

\subsection{Entity relationship diagram(ERD)}

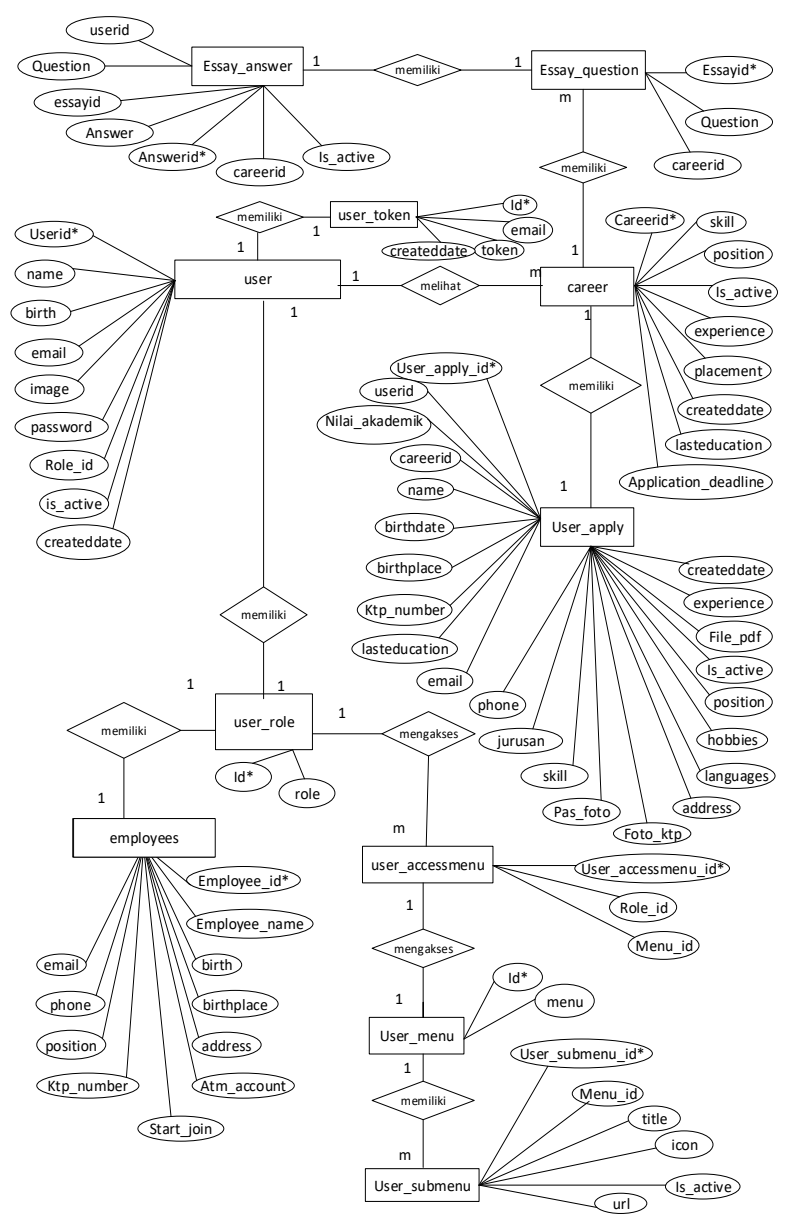

Gambar 7 gambar entity relationship diagram(ERD)

Diagram ERD pada gambar 7 menggambarkan hubungan relasi antar tabel. Dengan menggunakan basis data dengan nama webrekrutmen, basis data yang digunakan menggunakan 11 buah tabel yaitu tabel user, career, user apply, user role, employees, user accessmenu, user menu, user submenu, essay question dan terakhir essay answer.

\subsection{Logical record structure (LRS)}

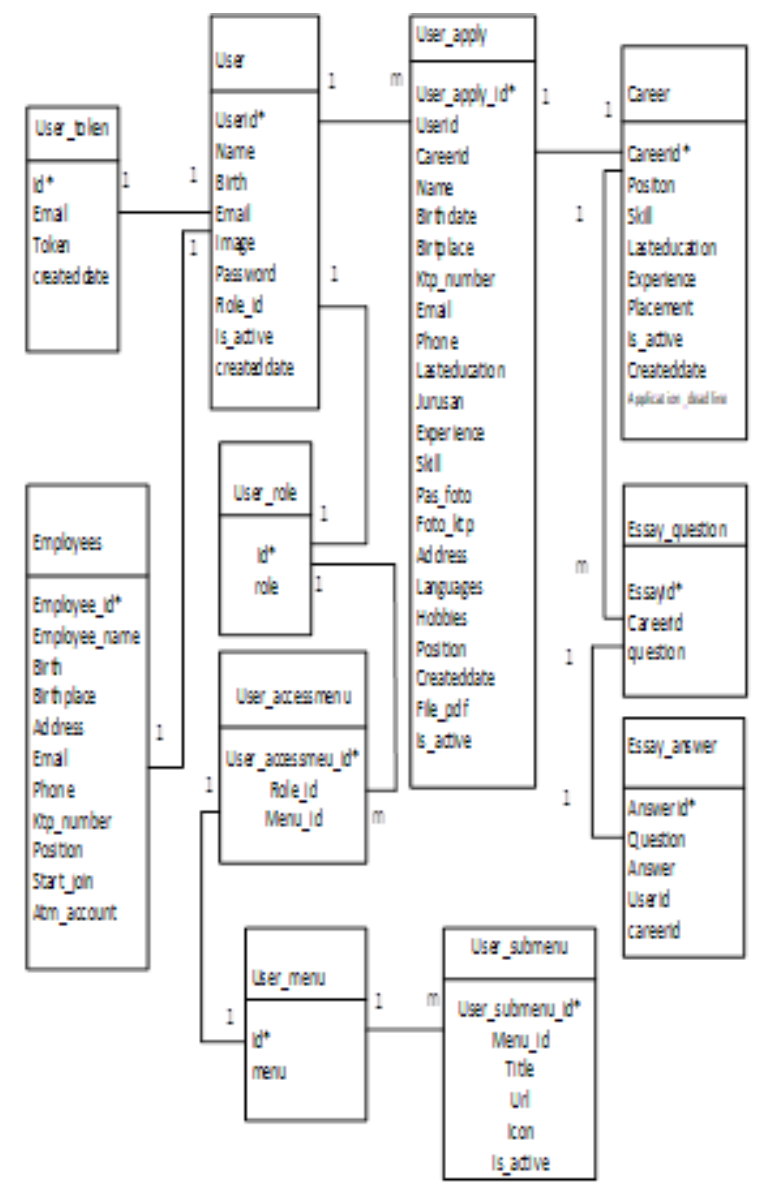

Gambar 8 gambar logical record structure (LRS)

Sama seperti gambar 7, pada gambar 8 menggambarkan struktur basis data dengan menggunakan 11 tabel. Nama-nama tabelnya yaitu tabel user, career, user apply, user role, employees, user accessmenu, user menu, user submenu, essay question dan terakhir essay answer.

\subsection{Implementasi}

a. Halaman Registrasi

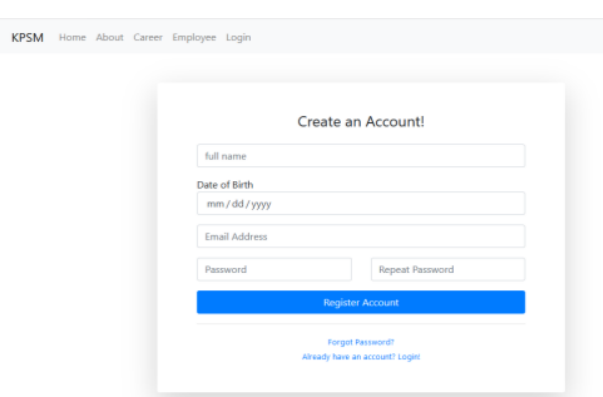

\section{Gambar 9 Gambar Halaman Registrasi}

Gambar 9 merupakan tampilan web dimana calon karyawan yang belum memiliki akun dapat melakukan registrasi akun dulu di halaman 
registrasi ini. Jika akun berhasil didaftarkan maka nantinya calon karyawan akan mendapat email untuk verifikasi akun yang telah didaftarkan.

b. Halaman login user

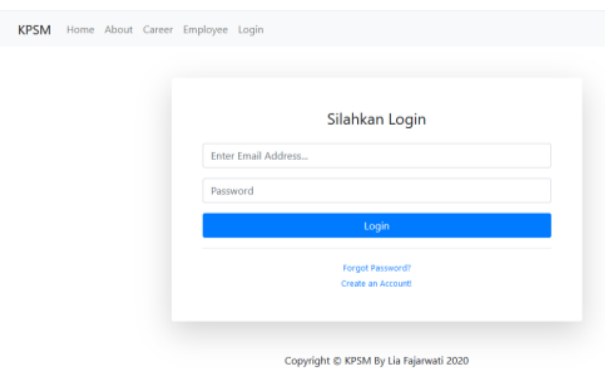

Gambar 10 gambar halaman login user

Gambar 10 menggambarkan tampilan halaman website dimana calon karyawan yang telah memiliki akun selanjutnya dapat login menggunakan email dan password yang telah didaftarkan. Jika pengguna belum memiliki akun, maka pengguna wajib registrasi terlebih dahulu untuk mendapatkan akun.

c. Halaman posisi lowongan kerja

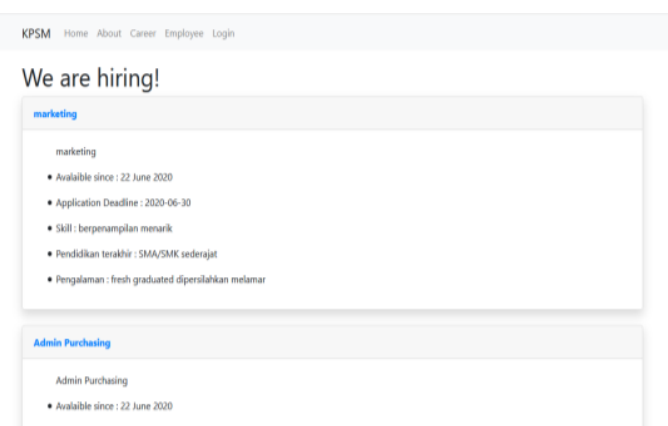

Gambar 11 gambar halaman posisi lowongan kerja

Gambar 11 merupakan tampilan posisi apa saja yang sedang dibutuhkan oleh perusahaan beserta persyaratannya. Di halaman ini, calon karyawan bisa meilih posisi sesuai dengan bidangnya masing-masing.

d. Halaman hrd/admin mengelola informasi lowongan kerja

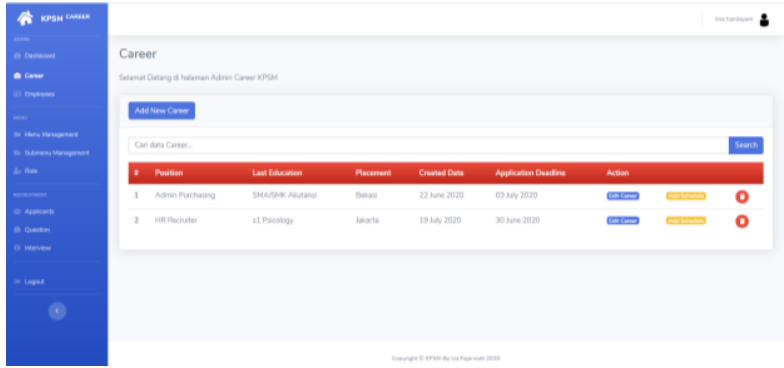

Gambar 12 gambar halaman HRD/Admin mengelola informasi lowongan kerja

Gambar 12 menggambarkan halaman dimana HRD dapat mengelola informasi lowongan kerja. HRD dapat menambah, menghapus, maupun memperbarui info lowongan kerja pada halaman ini. Selain itu, HRD juga dapat menentukan tanggal dibuka dan berakhirnya info lowongan kerja beserta persyaratan yang dibutuhkan untuk masingmasing posisi.

e. Halaman calon karyawan mengisi formulir lamaran kerja

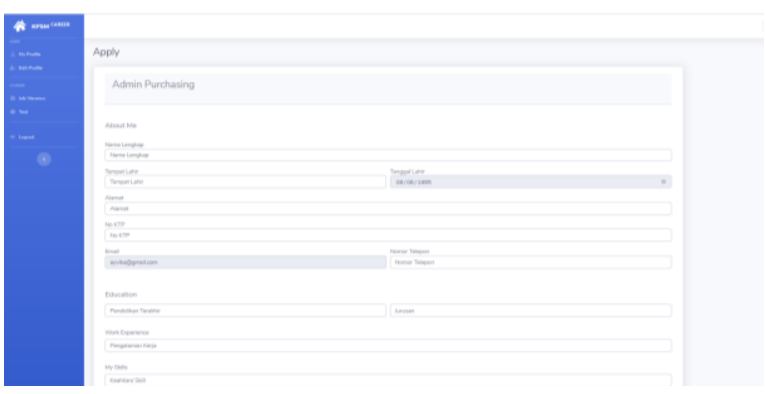

Gambar 13 gambar halaman calon karyawan mengisi formulir lamaran kerja

Gambar 13 menggambarkan halaman calon karyawan ketika hendak mengirim lamaran pekerjaan. Halaman ini berisi formulir dimana calon karyawan harus mengisi data seperti nama lengkap, tempat lahir, tanggal lahir, alamat, no ktp, no telp, pendidikan terakhir, jurusan, pengalaman, keahlian, kemampuan bahasa, hobi, pas foto, foto $\mathrm{ktp}$, file lamaran, dan nilai terakhir.

\subsection{Pengujian}

Pengujian merupakan bagian utama dari pengembangan software, karena kegagalan pengujian dapat menimbulkan kerugian yang besar (Aziz, Setiawan, Khanh, Nurdiyansyah, \& Yulianti, 2020).

a. Pengujian blackbox testing halaman pengiriman lamaran 


\begin{tabular}{|c|c|c|c|c|c|}
\hline No & $\begin{array}{l}\text { Skenario } \\
\text { Pengujian }\end{array}$ & Test Case & Hasil yang diharapkan & $\begin{array}{l}\text { Hasil } \\
\text { Pengujian }\end{array}$ & Kesimpulan \\
\hline 1 & $\begin{array}{l}\text { Semua kolom } \\
\text { dikosongkan }\end{array}$ & $\begin{array}{l}\text { Kolom nama lengkap, tempat } \\
\text { lahir, tanggal lahir, alamat, no ktp, } \\
\text { no telp, pendidikan terakhir, } \\
\text { jurusan, pengalaman, keahlian, } \\
\text { kemampuan bahasa, hobi, pas } \\
\text { foto, foto ktp, file lamaran, nilai } \\
\text { terakhir dikosongkan }\end{array}$ & $\begin{array}{l}\text { Tampil pesan bahwa nama lengkap, } \\
\text { tempat lahir, tanggal lahir, alamat, } \\
\text { no ktp, no telp, pendidikan terakhir, } \\
\text { jurusan, pengalaman, keahlian, } \\
\text { kemampuan bahasa, hobi, pas foto, } \\
\text { foto ktp, file lamaran, nilai terakhir } \\
\text { harus diisi. }\end{array}$ & Sesuai & valid \\
\hline 2 & $\begin{array}{l}\text { Semua kolom } \\
\text { dikosongkan } \\
\text { kecuali nama } \\
\text { lengkap }\end{array}$ & $\begin{array}{l}\text { Kolom tempat lahir, tanggal lahir, } \\
\text { alamat, no ktp, no telp, pendidikan } \\
\text { terakhir, jurusan, pengalaman, } \\
\text { keahlian, kemampuan bahasa, } \\
\text { hobi, pas foto, foto ktp, file } \\
\text { lamaran, nilai terakhir. Nama } \\
\text { lengkap diisi }\end{array}$ & $\begin{array}{l}\text { Tampil pesan tempat lahir, tanggal } \\
\text { lahir, alamat, no ktp, no telp, } \\
\text { pendidikan terakhir, jurusan, } \\
\text { pengalaman, keahlian, kemampuan } \\
\text { bahasa, hobi, pas foto, foto ktp, file } \\
\text { lamaran, nilai terakhir harus diisi }\end{array}$ & Sesuai & valid \\
\hline 3 & $\begin{array}{lr}\text { Semua } & \text { kolom } \\
\text { diisi } & \text { kecuali } \\
\text { kolom } & \text { nama } \\
\text { lengkap } & \end{array}$ & $\begin{array}{l}\text { Kolom tempat lahir, tanggal lahir, } \\
\text { alamat, no ktp, no telp, pendidikan } \\
\text { terakhir, jurusan, pengalaman, } \\
\text { keahlian, kemampuan bahasa, } \\
\text { hobi, pas foto, foto ktp, file } \\
\text { lamaran, nilai terakhir diisi dan } \\
\text { kolom nama lengkap dikosongkan }\end{array}$ & $\begin{array}{l}\text { Tampil pesan bahwa nama lengkap } \\
\text { harus diisi }\end{array}$ & Sesuai & valid \\
\hline 4 & $\begin{array}{lr}\text { Semua } & \text { kolom } \\
\text { diisi tetapi posisi } \\
\text { yang } & \text { dilamar } \\
\text { sudah } & \text { pernah } \\
\text { dilamar } & \end{array}$ & $\begin{array}{l}\text { Kolom nama lengkap, tempat } \\
\text { lahir, tanggal lahir, alamat, no ktp, } \\
\text { no telp, pendidikan terakhir, } \\
\text { jurusan, pengalaman, keahlian, } \\
\text { kemampuan bahasa, hobi, pas } \\
\text { foto, foto ktp, file lamaran, nilai } \\
\text { terakhir diisi }\end{array}$ & $\begin{array}{l}\text { Tampil pesan bahwa posisi yang } \\
\text { diinginkan sudah pernah dilamar }\end{array}$ & Sesuai & valid \\
\hline 5 & $\begin{array}{lr}\text { Semua } & \text { kolom } \\
\text { diisi dan } & \text { belum } \\
\text { pernah } & \\
\text { mengirim } & \\
\text { lamaran } & \text { pada } \\
\text { posisi } & \text { yang } \\
\text { tersedia } & \end{array}$ & $\begin{array}{l}\text { Kolom nama lengkap, tempat } \\
\text { lahir, tanggal lahir, alamat, no ktp, } \\
\text { no telp, pendidikan terakhir, } \\
\text { jurusan, pengalaman, keahlian, } \\
\text { kemampuan bahasa, hobi, pas } \\
\text { foto, foto ktp, file lamaran, nilai } \\
\text { terakhir diisi }\end{array}$ & $\begin{array}{l}\text { Pengiriman lamaran berhasil dan } \\
\text { menampilkan pesan bahwa lamaran } \\
\text { berhasil dikirim }\end{array}$ & Sesuai & valid \\
\hline
\end{tabular}

Tabel 1 tabel hasil pengujian blackbox testing halaman pengiriman lamaran

Tabel 1 merupakan table hasil pengujian halaman pengiriman lamaran. Jadi, jika semua kolom dikosongkan lalu calon karyawan mengirim lamaran maka lamaran tidak terkirim dan menampilkan pesan kesalahan. Jika calon karyawan mengisi hanya salah satu kolom dan mengirim lamaran maka lamaran juga tidak akan terkirim dan menampilkan pesan kesalahan.

Namun meskipun jika semua kolom diisi tetapi calon karyawan sudah pernah mengirim lamaran untuk posisi yang sama maka lamaran juga tidak terkirim dan menampilkan pesan bahwa posisi yang dilamar sudah pernah dilamar. Dan sebaliknya, jika calon karyawan mengisi semua kolom dengan benar dan posisi yang dilamar belum pernah dilamar sebelumnya maka lamaran akan terkirim. Jika lamaran terkirim, maka akan menampilkan pesan bahwa lamaran berhasil dikirim.

\section{Kesimpulan}

Kesimpulan yang penulis dapatkan dari sistem informasi rekrutmen karyawan pada PT Karya Putra Sapta Manunggal berdasarkan rumusan masalah yang telah dijelaskan sebelumnya yaitu:

a. Sistem informasi perekrutan karyawan memudahkan HRD untuk meminimalisir waktu, biaya dan tenaga sehingga proses rekrutmen menjadi lebih efisien.

b. Penyampaian informasi secara jelas dan terbaru akan membuat citra perusahaan menjadi semakin baik. 


\section{Referensi}

Abdulloh, Rohi. 2016. Easy \& Simple Web Programming. Jakarta: PT Elex Media Komputindo.

Aziz, I. A., Setiawan, B., Khanh, R., Nurdiyansyah, G., \& Yulianti, Y. (2020). Pengujian Black Box pada Aplikasi Sistem Kasir Berbasis Website Menggunakan Teknik Equivalence Partitions. Jurnal Teknologi Sistem Informasi dan Aplikasi, 3(2), $\quad$ 10.32493/jtsi.v3i2.4693. doi:10.32493/jtsi.v3i2.4693

Canggih Ajika Pamungkas. 2017. Dasar Pemrograman Web Dengan PHP. Yogyakarta: Deepublish.

Dedy Rahman Prehanto, S.Kom., M.Kom. 2020a. Buku Ajar Konsep Sistem Informasi. Surabaya: Scopindo Media Pustaka.

_ 2020b. Buku Ajar Model Sistem Pendukung Keputusan dengan AHP dan IPMS. Surabaya: Scopindo Media Pustaka.

Desanti, Ririn Ikana, and Andree E. Widjaja. 2018. "Aplikasi Perekrutan Dan Penilaian Karyawan Berbasis Web Pada PT. XYZ." Jurnal ULTIMA InfoSys 8(2): 74-80.

Eko Junirianto. 2018. Pemrograman Web Dengan Framework Laravel. Ponorogo: WADE Group.

Febrian, V., Ramadhan, M. R., Faisal, M., \& Saifudin, A. (2020). Pengujian pada Aplikasi Penggajian Pegawai dengan menggunakan Metode Blackbox. Jurnal Informatika Universitas Pamulang, 5(1), 61-66. doi:10.32493/informatika.v5i1.4340

Habibi, Roni, and Kurnia Sandi. 2020. Aplikasi Bank Sampah Istimewa Menggunakan Framework PHP Codeigniter Dan DBMS MySQL. Bandung: Kreatif Industri Nusantara.

Hariwijaya, H. 2017. Sukses Rekrutmen \& Seleksi Karyawan: Elmatera. Sleman: Diandra Kreatif.

M. FIRMAN ARIF, S.Kom., M.Kom. 2019. Analisis Dan Perancangan Sistem Informasi. Surabaya: Penerbit Qiara Media.

Mulyani, Sri. 2016. Analisis Dan Perancangan Sistem Informasi Manajemen Keuangan Daerah. Bandung: ABDI SISTEMATIKA.

Supono, and Vidiandry Putratama. 2018. Pemrograman Web Dengan Menggunakan PHP Dan Framework Codeigniter. Yogyakarta: Deepublish.

Taufiq, Rohmat. 2018. Pengantar Sistem Informasi. Jakarta: Mitra Wacana Media.

Yulistia, Ricki Andira Lesmono, and Rendi Harefa. 2020. "Sistem Pendukung Keputusan Penerimaan Pegawai Menggunakan Metode AHP ( Analytical Hierarchy Process ) Hotel RC Di Palembang." JTSI 1(1): 65-72.

Yurindra. 2017. Software Engineering. Yogyakarta: Deepublish. 